\title{
Effectiveness of Educational Combination of Marital Relation on Reducing Conflict Marital and Improvement of the Quality of Life for Women
}

\author{
Mozhgan Rafiee ${ }^{1} \&$ Hossein Davoodi ${ }^{2}$ \\ ${ }^{1}$ Master of Science Student, Department of Consultation, Faculty of Humanities, Khomein Branch, Islamic Azad \\ University, Tehran, Iran \\ ${ }^{2}$ Assistant Professor, Department of Consultation, Faculty of Humanities, Khomein Branch, Islamic Azad \\ University, Tehran, Iran \\ Correspondence: Hossein Davoodi, Department of Consultation, Faculty of Humanities, Khomein Branch, \\ Islamic Azad University, Tehran, Iran. E-mail: esfehani.mohamad3@gmail.com
}

Received: June 27, 2016

Accepted: July 8, 2016

Online Published: August 6, 2016

doi:10.5539/mas.v10n12p107

URL: http://dx.doi.org/10.5539/mas.v10n12p107

\begin{abstract}
This study was carried out with the objective of evaluating the effect of combined Effectiveness of 1 And 2 Educational Combination Relation Marital Skills (Speaking and listening to each other) and (moving forward together) On Reducing Marital Conflict And Improving The Quality of Life For Women of Mahmudabad city. The statistical population of the research were 80 housewives under the support of Welfare Organization of Mahmoud Abad city who had records in 2014-15 among whom 20 individuals were randomly selected as statistical sample using available sampling. 10 individuals were randomly assigned to the experimental group and 10 individuals were assigned to the control group. Research tools were marital conflicts' questionnaire with 42 items (Barati \& Snaie, 1996) and quality of life questionnaire with 26 questions (WHOQ-REFB) of the world Health Organization. The results of the study showed that integrated teaching of 1 and 2 marital communication skills (taking and listening to each other) and (moving forward together) has had no effect on reduction of marital conflicts and improvement of quality of life of woman.
\end{abstract}

Keywords: marital conflict, quality of life

\section{Introduction}

Psychological View of the method of human relationships is important in many ways. A significant part of the moral and character development characteristics of smaller and older individuals is a result of the method of communication and relationship between them. A more honest and more respectful and more productive and enlightening relationship provide a greater field of mental health and sanity and satisfaction and relaxation (Afrouz, 2003).

Women make up half the population of the whole world and their health is the foundation of healthy families and societies. The problems of women affect the physical and mental health of family, society, and even future generations. Hence, the study of quality of life and health of women is very important and has attracted a lot of researchers in the field of quality of life. A brief overview of those show that each of these researches have considered different aspects of quality of life (Bayat \& Bayat, 2013).

In general, there is an inverse relation between ages of spouse at marriage and the likelihood of divorce. Those who marry at a very young age experience the highest rate of divorce which is probably because they did not have enough communication skills and maturity (Navabi, 2009).

Soo \& Soo (1990) believe that in comparison with the dominant culture in the United States of America almost all minority groups have a great value for family and lineage and descendants, interpersonal relationships with family members and priority of family over the individual. The fact that the prevailing culture relies on individualism means that people with culture which has stronger communication aspect may be under pressure for conformity and compliance. Women as a cultural group are also under pressure to adapt to changing views about the meaning of healthy behavior (Nazari, 1997). 
Quality of life is a sense of satisfaction or dissatisfaction about various and important aspects of life which includes psychological, social, economic and family fields. Nowadays, we face the topic of marital relationship in evaluation of quality of life for people which is one of the strongest human relationships and the form of these relationships have various outcomes for spouses, children and other family members and the society (Matlabi, 2001; Bayat, 2013).

Due to the fact that people see the world in very different views and have different goals, conflicts is an integral and inevitable part of human relationships. In fact, more intimate relationship increase the likelihood of interpersonal conflict. The important point is that if we want to have dynamic and alive relationship, we must solve these disputes in the right way. Although conflict may statistically be normal but it should not be suppressed and ignored. The verbal conflict is not only acceptable but is also desirable. According to them, couples who fight with each other will stay together because they know to fight more reasonably with each other. Couples who do not fight and therefore do not solve their problems may be face diverge in emotional terms (Beach, 1969; Olson \& Olson, 2001). Conflict is an inevitable part of human relationships.

Marital Communication reviews roots date back to the late ' 60 s at the center of family studies at the University of Minnesota. There, experts such as sherad, Miller, Nunnally and Wacman met each other and formed a Research and Planning team thanks to the ingenuity of thought and basic research inspired by the National Institute of Mental Health. Their initial research was related to transition (transfer) from engagement to the early marriage and conditions that support couples in this successful transition. The main core of effective communication is the change process in this research (Bahari, 2011).

In recent years, a considerable attention have been paid to the measurement of health of individuals and the influence of psychological and physical disease on daily activities and their behaviors which have been focused on an attitude and a holistic approach in health and health cares and new approach has been proposed in this regard in medical and social researches named the quality of life (Bayat \& Bayat, 2013).

Marital discord are affective a wide range including individual, couple and biological factors. These factors are dynamic and change over the relationship between a husband and wife. Complex medical interventions should clinically include all of these factors. Husband and wife must reduce their anxiety as much as possible as a partner in the current relationship and thus, improve the performance in relation. For this purpose, it is necessary for education system to be developed and ways to prevent a crisis in the relationship such as infidelity and prevention of mental suffering on both sides become the agenda. This trainings can be in the form of continued commitment, identifying the situation and development and optimization of relations between two sides (Dobson, 2010).

It became clear in a correlation study about the health of the mothers that lower level of education has been associated with increased mortality, poverty, unemployment, inadequate housing and poor health behaviors (Fritzella, 2007; quoted Bayat, 2013).

Early signs of impending conflict escalation may include emotional arousal, a pattern of verbal accusing or mentioning sensitive issues. The therapist must help the couple to detect warning signs in the initial phases as soon as possible. Regardless of the progress or skill level that couples will have, some returns to previous negative patterns will inevitably happen. One of the ways to reduce returning contains two basic components:

1) Prediction and intervention to prevent situations or behaviors that increase the likelihood of to returning;

2) Creating strategies to help patients to be able to prevent a full return by removing small obstacles.

Many studies have evaluated the effectiveness of cognitive-behavioral marriage therapy which were usually limited to interchange interventions of behavior and problem-solving $\mathrm{d}$ communication. Although the effectiveness of newer forms of cognitive-behavioral marital therapy requires researches, evaluation of studies related to the treatment outcomes obtained from the previous approaches of this type (Baucom \& Hafman, 1986) is effective in suppression of discomfort to a good extend. It seems that this type of treatment is completely effective in the type of treatment, reducing communication problems, reducing reported target backgrounds and increasing the marital satisfaction (Kirk et al., 1998, quoted by Ghasem Zadeh, 2012).

Constructivism believe that Family Flexibility is extremely important in adapting to changes is the growth and unexpected crisis situation and believe that family members simply join each other to solve conflict (Goldenberg $\&$ Goldenberg, 1934). The use of modern procedures in marital conflict resolution and conflict management are among the indicators of this theory which will certainly reduce marital conflict (quoted by Shahryari, 2008).

People who have high emotional intelligence look at the stressful events as a challenge and an opportunity to learn and not as a threat to security and thus suffer less physiological disorders and emotional experience and 
therefore have a higher quality of life (Yousefi \& Safari, 2009).

A research carried out by Heydari (2009) has shown that effective dialogue program has made Joint decision-making to be a part of mental system of couples because of its structure and has turned the strict rules to flexible rules and thus, it increases marital satisfaction and positive and intimate between couples by improving skill of couples in conflict resolution and thus, it significantly affects the improvement of sexual relationship.

The results of the study of Shahriari (2008) showed that there is a significant difference between couples of the experimental group who received family therapy interventions and the control group who did not receive interventions in terms of marital conflict.

Sources conflict change over time. Badr et al have collected data about conflicts of couples over a period of 5 years. Researchers interviewed couples just before marriage and interviewed them again 6 months and 1 year and 5 years after marriage. Before marriage, jobs of husbands and issues of devoting time and attention (care and love) were respectively the most important issues causing conflict. Housework was the first source of conflict 6 months after the marriage, the second source was revenues and spending money and time and attention were the third source of conflict. At the end of the first year of marriage, housework, time and attention and revenues and spending money were respectively considered to be the most important sources of conflict and at the end of the fifth year, housework and the time and attention were identified as the primary sources but the sexual issues had jumped from thirteenth place to third place. The researchers concluded that the main tasks of living together and method of dividing housework, method of spending time and paying attention to each other, method of revenues and spending money and the related issues cause the most conflict for couples (Olson \& Olson, 2001; quoted from Shiri, 2008).

We must move toward focusing on emotional processes to improve the marital relationship in the cognitive and behavioral fields (Friezity, 2006; Johnson, 2004; Janson \& Dentone, 2002; Dobson, 2010).

Gordone (2000) believed therapeutic interventions based on modification of interpersonal interactions and teaching behavioral skills to be useful and effective in reducing marital distress (According to Dobson, 2010).

Hansoon \& Lundbland (2006) taught the communication skills and conflict resolution to couples who had trouble interacting with each other and were dissatisfied with their lives and the obtained results showed that these trainings will significantly improve the relations of couples and the ability to cope mental health problems (quoted by Amani \& Latafi, 2013).

Epstein (2006) concluded in his study about psychopathology in couple's issues that unresolved individual issues in each of the spouses can cause stress and depression and restrictions on intimacy in their relationship. For example, if one spouse has the feeling of being freed and the need for kindness and repeated requests for attention and assurances in his or her early experiences, it can cause crisis in the relationship between them and their behavior turn into turmoil and intense distress as a consequence (According to Dobson, 2010).

Kira S. Birditte \& Eth (2010) concluded in a study that Family therapy sessions according to self-reporting forms during 16 years showed that negative and dysfunctional behaviors and the main roots of separation of spouses in long-term have been related to Interpersonal Relationships and patterns of false relationships between couples.

Vang \& Vang (2014) concluded in a study that unresolved conflicts among spouses over the long time have negative impact on their mental health and threaten other areas of a marital relationship.

Joaning (2009) has evaluated the long-term effect of group training on couples with marital conflict. The results of this research indicate the increased marital satisfaction even after 5 months of training in the follow-up period (quoted by Amani \& Latafi, 2013).

Thus, the present research tried to answer this question that is teaching compilation marital relationship skills affective on reduction of marital conflicts and improvement of the quality of life of women?

\section{Method}

\subsection{Statistical Population, Sample and Research Method}

The statistical population of the research were 80 housewives under the support of Welfare Organization of Mahmoud Abad city who had records in 2014-15 among whom 20 individuals were randomly selected as statistical sample using available sampling. 10 individuals were randomly assigned to the experimental group and 10 individuals were assigned to the control group and teaching of consolidated marital relationship skills was carried out for the experimental group in 10 sessions with 90 minutes and the control group did not receive any training. 
First session: brief Referrals including members communicating with each other, reason for referral or being referred and description of meetings.

Second session: implementation of the pre-test for marital conflict questionnaire and quality of life and knowledge of members to the issues and how they handle it.

Third Session: Understanding the foundations of healthy relationships: healthy and unhealthy attitude (Cycle of knowledge) and speaking skills including the self-talk, speaking on his own behalf, describing sensory information, expression of thoughts, feelings, words, desires, sharing proceedings.

Fourth Session: Learning the five main listening skills including paying attention, acknowledging, inviting, summarizing, and questioning the spouse.

Fifth Session: Introduction to four common styles of marital relationship:

1) Chatting-formal listening;

2) Hegemonic talking- reactive listening;

3) Exploratory talking- exploratory listening;

4) Clear talking- listening with attention and the marital relationship map.

Sixth Session: relationship based on cooperation and teaching methods of communication and interaction processes.

Seventh Session: harnessing the anger and learning ways to express anger and harness anger.

Eighth Session: Responding to anger of spouse and learning the steps of anger of spouse.

Ninth Session: the steps of relationship and learning the characteristics of each step.

Tenth Session: completing the marital conflict and quality of life questionnaires in form of post-test by members under the supervision of the researcher.

The research method has been semi- experimental by pretest-posttest design with the control group. In a way that housewives without any marital communication skills were place in two experimental and control groups. In this study, 1 and 2 marital relationship skills were considered as independent variables and reduction of marital conflicts and quality of life were considered as dependent variables.

\section{Measurement Tools}

Marital conflict questionnaire: it has been prepared by Barati (1996) based on clinical experiences and cooperation of Sanaee (1996). This tool has 42 items and has been created with the objective of measuring marital conflicts. Items of this tool are along with 5 options of always, most often, sometimes, rarely or never which have respectively the scores of 1 to 5 . A high score means severe marital conflicts and a low score means the lack of conflict. The reliability of this questionnaire for the whole questionnaire is equal to $53 \%$ using Cronbach's alpha method.

The questionnaire of Quality of Life: is a toll which has 26 items. The Cronbach's alpha coefficient has been reported to be 0.89 in the results reported by creator group of the World Health Organization Quality of Life Scale which has been carried out in 15 international centers of this Organization. In Iran, Nasiri (2006) used three methods of three-week retesting, split-half and Cronbach's alpha which were respectively equal to 0.67 , 0.87 and 0.84

\section{Findings}

Table 1. The descriptive findings of variables of the experimental group $(n=10)$

\begin{tabular}{lllllllllll}
\hline Pre-test & \multicolumn{10}{c}{ Post-test } \\
\hline & Mean & Median & SD & Minimum & Maximum & Mean & Median & SD & Minimum & Maximum \\
Marital conflicts & 167.6 & 170 & 21.5 & 124 & 197 & 167.7 & 167 & 20.36 & 142 & 202 \\
Quality of Life & 82.9 & 79 & 16.03 & 59 & 114 & 83.7 & 82 & 12.5 & 65 & 101 \\
\hline
\end{tabular}


Table 2. The descriptive findings of variables of the control group $(n=10)$

\begin{tabular}{llllll|lllll}
\hline Pre-test & & \multicolumn{7}{l|}{} & Post-test \\
\hline $\begin{array}{l}\text { Marital } \\
\text { conflicts }\end{array}$ & 160.4 & 159 & 18.9 & 120 & 184 & 172.7 & 174 & 17.8 & 140 & 197 \\
$\begin{array}{l}\text { Quality } \\
\text { of Life }\end{array}$ & 65 & 66 & 6.8 & 49 & 75 & 69 & 69 & 7.4 & 50 & 79 \\
\hline
\end{tabular}

Table 3. Reviewing the normality of assumptions and equality of variances

\begin{tabular}{lllll}
\hline K-s test & & \multicolumn{3}{c}{ Levine test } \\
\hline \multirow{2}{*}{ Marital conflicts } & $\mathrm{z}$ & sig & f & Sig \\
& 0.71 & 0.77 & 0.28 & 0.62 \\
Quality of Life & 0.68 & 0.59 & 0.14 & 0.7 \\
\hline
\end{tabular}

Table 4. The summery of the test of slope equality of the regression line

\begin{tabular}{llllll}
\hline Source of changes & Sum of squares & Degree of freedom & Mean Square & $\mathrm{f}$ & $\mathrm{Sig}$ \\
\hline Covariate & 1252.12 & 1 & 1252.12 & & \\
Interaction & 19 & 1 & 19 & 0.057 & 0.81 \\
remaining error & 5344 & 16 & 334 & & \\
\hline
\end{tabular}

The interaction between experimental conditions and covariate variables are not significant. In other words, the slope of the regression line is the same for both test conditions.

Table 5. Summary of analysis of covariance test for the effectiveness of training

\begin{tabular}{llllll}
\hline Source of changes & Sum of squares & Degree of freedom & Mean Square & $\mathrm{f}$ & Sig \\
\hline Covariate & 12.33 & 1 & 12.33 & & \\
Interaction & 406 & 1 & 306 & 0.97 & 0.33 \\
remaining error & 5463 & 17 & 315.4 & & \\
\hline
\end{tabular}

The results of one way covariance test showed that the main effect of effectiveness variable of the training is not significant on the scores of marital conflicts in the post-test by removing the effect of pretest scores as covariate change. Thus, the null hypothesis is confirmed and the contrary hypothesis stating the effectiveness of integrated teaching of 1 and 2 marital communication skills (taking and listening to each other) and (moving forward together) on reduction of marital conflicts of women is not confirmed.

Evaluation of the second hypothesis: Effectiveness of integrated teaching of 1 and 2 marital communication skills (taking and listening to each other) and (moving forward together) affects the improvement of quality of life of women.

Table 6. The summery of the test of slope equality of the regression line

\begin{tabular}{llllll}
\hline Source of changes & Sum of squares & Degree of freedom & Mean Square & f & Sig \\
\hline Covariate & 283 & 1 & 283 & & \\
Interaction & 58 & 1 & 58 & 1.02 & 0.32 \\
remaining error & 909 & 16 & 56.8 & & \\
\hline
\end{tabular}

The interaction between experimental conditions and covariate variables are not significant. In other words, the slope of the regression line is the same for both test conditions. 
Table 7. Summary of analysis of covariance test for the effectiveness of training

\begin{tabular}{|c|c|c|c|c|c|c|}
\hline $\begin{array}{ll}\begin{array}{l}\text { Source } \\
\text { changes }\end{array} & \text { of } \\
\end{array}$ & Sum of squares & $\begin{array}{l}\text { Degree } \\
\text { freedom }\end{array}$ & of & Mean Square & $\mathrm{f}$ & Sig \\
\hline Covariate & 934 & 1 & & 934 & \multirow{3}{*}{1.06} & \multirow{3}{*}{0.31} \\
\hline Interaction & 60.4 & 1 & & 60.4 & & \\
\hline remaining error & 967.6 & 17 & & 56.92 & & \\
\hline
\end{tabular}

The results of one way covariance test showed that the main effect of effectiveness variable of the training is not significant on the scores of marital conflicts in the post-test by removing the effect of pretest scores as covariate change. Thus, the null hypothesis is confirmed and the contrary hypothesis stating the effectiveness of integrated teaching of 1 and 2 marital communication skills (taking and listening to each other) and (moving forward together) on the improvement of quality of life of women is not confirmed.

\section{Discussion}

The statistical findings obtained from the present study showed that integrated teaching of 1 and 2 marital communication skills (taking and listening to each other) and (moving forward together) has had no effect on reduction of marital conflicts and improvement of quality of life of woman. Findings of the present study are against the findings of Miller et al. (1991), Goldenberg \& Goldenberg (1934), Smith (2009), prince (2008), Baucom \& Gordon (2010), Baucom \& Hoffman (1986), Kirk et al. (1976), Hanson \& Long-Land (2006). The mentioned studies have shown that teaching communication skills have been effective in reducing marital conflict and increasing marital satisfaction.

The obtained results can be explained based on the theory of constructivism (Goldenberg \& Goldenberg, 1934), Shahryari (2008) based on the use of modern procedures in marital conflict resolution and conflict management which will reduce the marital conflict. The obtained results can be also explained based on the cognitive behavioral approach. They believe that the signs of increasing conflict among couples can include emotional arousal, a pattern of verbal accusing or turning to sensitive issues which can cause moving back towards negative patterns. Thus, methods must be used which can reduce the returning based on 1) prediction and intervention and 2) creation of strategies to help patients which can prevent the full returning by removing small obstacles (Baucom \& Hoffman, 1986; Kirk et al., 1998; Ghasem Zadeh, 2012).

Research suggestions obtained from the findings of the present study are in line with the results of the studies of (2006), Johnson (2004), Johnson \& Denton (2002), Yousefi \& Safari (2009). Because they have reported that we must move toward focusing on emotional processes of the couple therapy in order to improve the marital relationship in the cognitive and behavioral fields (Friezity, 2006; Johnson, 2004; Johnson \& Denton, 2002).

We must express in explanation of these results that $t$ couples therapists often evaluate the couples based on their limited knowledge, while for understanding, not only the individual aspects of the family, but the family as a whole unit needs comprehensive and accurate assessment of the situation (Navabi, 2009).

The results of studies of Yousefi and Safari (2009); Olson and Olson (2001), quoting assorted (2008), Epstein (2000), quoted Dobson (2010), Bahari (2011) are in line with the research suggestions of the present study stating that factors such as high emotional intelligence with frequency of physiological and emotional disorders and evaluation of individuals in terms of individual psychopathology and unresolved issues in long time which can be said can cause stress and depression and limited intimacy in both spouses and cause crisis in the relation and lead couple's performance in response behavior to turmoil and intensified distress (Epstein, 2000; quoted in Dobson, 2010).

The results of the studies of Joaning (2009) to the trust and tenderness (2013) and Vang \& Vang (2014), Cross, Biredit et al. (2010), Olson \& Olson (2001), quoting from a Shiri (2008), Dobson (2010) with the limitation of being cross-sectional are in line with the research suggestion of the present study stating that the future studies must be longitudinal. Sources of conflict change over time (Olson \& Olson, 2001; quoted from a Shiri, 2008). It must be expressed in explanation of this isSoo that Family therapy sessions which were carried out based on self-reporting form during 16 years showed that Negative and dysfunctional behaviors of couples and the roots of separation in long-term have been related to interpersonal communication and the wrong pattern of relationships between couples which has affected their mental health (Kraus et al., 2010).

Vang \& Vang (2014); Joaning (2009), quoted by Amani \& Latifi (2013) reported the long-term effect of couples group training to be effective in increasing the marital satisfaction. Thus, the short term and intensive training of marital relationship skills in conflict resolution and enhanced quality of life is successful. 


\section{References}

Afrouz, Gh. (2003). Psychology of relationships (3rd Ed.). Tehran: Tehran University Press.

Amani, A., \& Beris Letafati, R. (2013). The effectiveness of communication skills training to reduce marital conflict. Practical Advice Journal, 3(2), 36-17.

Bach, G. R., \& Wyden, P. (1963). The intimaten enemy. Newyork: Avon Boors.

Baghmalek, Sh., Younes, \& Shafiabadi, A. (2008). Master's thesis.

Baucom, D. H., \& Hoffman, J. A. (1986). The effectiveness of marital therapy: Current status and application to the clinical setting. N. S. Jacobson \& A. S. Gurman (Ed.). Clinical handbook of marital therapy (pp. 597-620). New York: Guilford Press.

Baucom, D. H., Epstein, N., \& Gordon, K. C. (2000). Marital therapy: Theory, practice, and empirical status. C. R.

Bayat, \& Bayat (2013). Book strategic ideas wife and family, the seventh axis, the role of women in the family, check the quality of women's lives in the holy city of Mashhad. National Library of the Islamic Republic of Iran.

Dobson, K. (2010). The Gilford Press, New York / London.

Fruzzetti, A. E. (2006). The high-conflict couple: A dialectical behavior therapy guideto finding peace, intimacy, and validation. Oakland: Harbinger.

Goldenberg, I., \& Goldenberg, H. (1934). Treating the dual career couple. American Journal of Family Thrapy, 12, 29-37.

Heidari, H., Sanaei Zaker, B., Navabinejad, Sh., \& Delavar, A. (2009). The effectiveness of the dialogue on reducing marital conflicts. Thoughts and Behavior, 4(14).

Houghton, K. (2010). Cognitive Behavior Therapy: A Practical Guide for the treatment of mental disorders (Habibullah Ghasem Zadeh, Trans.). Tehran: Arjmand.

John, K., Len, A., \& Judith, L. (2009). Family Therapy: To ensure efficient management (Shokouh Navabinejad, Trans.). Center for Family Studies and Research.

Johnson, S. M. (2004). The practice of emotionally focused marital therapy: Creatingconnection (2nd Ed.). New York: Routledge.

Johnson, S. M., \& Denton, W. (2002). Emotionally focused couple therapy: creating secure connections. In A. S. Gurman \& N. S. Jacobson (3rd Eds.), Clinical handbook of couple therapy (pp. 221-250). New York: Guilford Press.

Joining, H. (2009). The long term effects of the couple communication program. Journal of Marital \& Family Therapy, 8(4), 493-498.

Kira, S., \& Birditt, E. (2010). Marital conflict Behaviors and implications for Divorce over 16years. Journal of Marriage and Family, 74(5), 1188-1204.

Kirk, E. (1998). Gognitive Behaviour therapy for psychiatric problems A Practical Guide.

Miller, S., \& Miller, P. E. (1991). Talking and listening together: Couple Commounication 1. Evergreen, Colorado: Interpersonal Communication programs.

Miller, X. et al. (2011). Marital communication skills: talking and listening to each other, translated by Farshad Bahari. Roshd Publications.

Nasiri, H. A. (2006). Study Reliability and Validity of the World Health Organization quality of life and make the Iranian version. Proceedings of the Third Seminar on mental health of students, 3 and 4, June.

Nazari, A. M. (2007). Foundations of family therapy and couples therapy. Tehran: Science Publication.

Nazari, A. M. (2013). Summary of couple therapy and family therapy book.

Olson, H., \& Defrain, J. (2001). Marriages and families (intimacy, Diversity and strengths) (4th Eds.). KenthKing, New York.

Sanaei, \& Zaker, B. (2000). Marriage and family assessment scales. Tehran: Besat Publications.

Snyder, \& Ingram, R. E. (Eds.). Handbook of psychological change: Psychotherapy processes and practices for the 21 st century (pp. 280-308). New York: Wiley. 
Sue, D. W., \& Sue, D. (1990). Counseling the culturally different: theory and practice. NewYork: john wiley \& Son.

Wang, Q., Wang, D., Li, C., \& Miller, R. B. (2014). Marital satisfaction and Depressive symptoms among Chinese older couples. Again \& Mental Health, 18(1), 33-39.

Youssefi, F., \& Safari, H. (2009). Examine the relationship between emotional intelligence and the quality of life and its dimensions. Psychological Studies, 5(4).

\section{Copyrights}

Copyright for this article is retained by the author(s), with first publication rights granted to the journal.

This is an open-access article distributed under the terms and conditions of the Creative Commons Attribution license (http://creativecommons.org/licenses/by/4.0/). 